\title{
ANALISIS PROFITABILITAS DALAM MENINGKATKAN KINERJA KEUANGAN PADA PT BANUL DI KOTA PALOPO
}

\author{
HURRIAH, ANDI HASBI MUNARKA, HAPID
}

\begin{abstract}
ABSTRAK
Profitabilitas adalah kemampuan suatu perusahaan untuk menghasilkan keuntungan dibandingkan dengan modal yang digunakan dan dinyatakan dalam prosentase. Profitabilitas berfungsi sebagai alat untuk mengukur efektivitas manajemen seperti ditunjukkan oleh laba yang dihasilkan dari penjualan dan pendapatan investasi. Jadi tidak mesti suatu perusahaan yang keuntungannya lebih tinggi secara otomatis dapat menyebabkan profitabilitas yang tinggi juga, sebab dapat saja terjadi sebaliknya.

Tujuan penelitian ini adalah untuk mengetahui dan menganalisis tingkat profitabilitas dalam meningkatkan kinerja PT.Banul di Kota Palopo. Metode penelitian yang digunakan yaitu metode penelitian pengamatan. Data yang digunakan adalah data primer dan data sekunder.

Berdasarkan hasil penelitian, tingkat profitabilitas PT.Banul dapat dihitung dengan menggunakan laporan laba rugi setiap bulan. Hasil laporan laba rugi tersebut kemudian dianalisis dengan menggunakan persamaan yang sudah berlaku umum, yaitu profitabilitas = laba bersih dibagi pendapatan.

Kesimpulan bahwa analisis profitabilitas dapat meningkatkan kinerja keuangan PT.Banul di Kota Palopo, disarankan kepada Direktur PT.Banul agar tetap mempertahankan laba sesudah pajak yang dicapai sekarang dan ditingkatkan ratio profitabilitasnya, dengan cara menghemat biaya dan meningkatkan pendapatan dari bisnis rental mobil.

Kata kunci: Analisis Profitabilitas, Peningkatan Kinerja Keuangan
\end{abstract}




\section{Pendahuluan}

\section{Latar Belakang}

Karakteristik setiap perusahaan swasta adalah berupaya meningkatkan pendapatan dan meminimalkan pengeluaran agar dapat memperoleh laba yang optimal. Banyak perusahaan yang semula tumbuh dengan pesat tetapi kemudian gagal atau bangkrut akibat berbagai hal antara lain manajemen yang kurang baik dalam perencanaan dan pengelolaan keuangan perusahaan.

Laporan keuangan merupakan salah satu sumber informasi keuangan yang sangat penting sebagai alat pertanggungjawaban dan pengambilan keputusan, baik pihak internal maupun pihak eksternal perusahaan.

Setiap perusahaan selalu mengharapkan arus kas masuk (cash flow) lebih besar dari pada arus kas keluar (cash outflow) agar memperoleh arus kas bersih (laba) yang optimal. Arus kas bersih (net cash flow) menjadi pusat perhatian dalam analisis investasi karena; 1) Laba dalam pengertian akuntansi tidak sama dengan arus kas bersih, 2) Para investor dan manajer lebih tertarik pada besarnya arus kas bersih yang benar - benar diterima (tunai) sebab menunjukkan kemampuan perusahaan untuk membayar kembali investasi yang telah dikeluarkan (modal awal), 3) Perusahaan mampu membayar pokok pinjaman dan bunga, pajak, dividen, dan melakukan investasi kembali di masa yang akan datang.

Dalam keputusan investasi adalah memahami secara mendalam antara hasil yang diharapkan dengan resiko investasi. Hubungan antara resiko dan laba yang diharapkan dari suatu investasi merupakan hubungan yang searah dan linear, artinya semakin besar laba yang diharapkan, makin besar pula resiko yang akan terjadi. Demikian pula sebaliknya, jika mengharapkan laba kecil, maka resikonya juga kecil.

Analisis profitabilitas pada rrental mobil sangat besar resikonya karena barang bergerak, namun cukup banyak orang yang menggeluti bisnis tersebut. Dengan demikian, maka masalah ini sangat menarik untuk diteliti secara sistematis dan mendalam guna mengetahui tingkat laba yang dpat menambah modal dengan judul "Analisis profitabilitas dalam meningkatkan kinerja pada PT.Banul di Kota Palopo". Masalah dalam penelitian ini adalah seberapa besar tingkat profitabilitas yang dapat meningkatkan kinerja PT.Banul di Kota Palopo?. Tujuan penelitian ini adalah untuk mengetahui dan menganalisis tingkat profitabilitas dalam meningkatkan kinerja PT.Banul di Kota Palopo.

\section{Metode Penelitian}

Tempat dan Waktu Penelitian

Penelitian ini dilakukan pada PT.Banul yang bergerak di bidang mobil rental. PT.Banul beralamat di jalan Mungkasa nomor 9 Kota Palopo. 
Jenis dan Sumber Data

1. Data Primer

2. Data Sekunder

Metode Pengumpulan Data

Metode pengumpulan data yang digunakan adalah: (a) Wawancara; Wawancara dilakukan kepada pimpinan perusahaan tentang berbagai macam biaya operasional, sumber dana modal kerja, dan modal investasi, (b) Pengamatan; Pengamatan yang digunakan yaitu melakukan pengamatan langsung pada objek yang diteliti.

Metode Analisis Data

Metode analisis yang dapat membahas penelitian ini adalah sebagai berikut : Laba Bersih

Profotabilitas $=\frac{\text { Total Penjualan }}{\text { Laba Bersih }} \times 100 \%$
Rentabilitas $=\frac{\text { Total Asset }}{100 \%}$

\section{Hasil Penelitian Dan Pembahasan}

\section{Hasil Penelitian}

PT.Banul memiliki karyawan atau tenaga kerja, direktur, bendahara, dan bagian pemasaran masing - masing 1 orang, sopir mobil rental 3 orang, dan bagian pemeliharaan atau kebersihan mobil 2 orang. Dengan demikian total karyawan sebanyak 8 orang.

Jumlah mobil yang siap disewakan sebanyak 15 unit, yaitu Toyota Avansa 6 unit, Toyota Rush 6 unit, Toyota Innova 1 unit, Toyota Fortuner 1 unit, dan Nissan Extrail 1 unit. Pemakaian mobil yang dirental rata - rata pembuatan tahun 2009 dan 2010 dengan kondisi yang sangat prima.

Penetapan tarif sewa mobil rental sangat bervariasi, tergantung pada tipe mobilnya dan lama pemakaian setiap jamatau setiap hari. Tarif juga dipengaruhi oleh sopir, artinya jika pakai sopir sendiri maka tarifnya akan lebih murah daripada menggunakan supir dari perusahaan. 
Tabel 01

Daftar Tarif Rental Mobil PT.Banul Palopo

Tahun 2010

\begin{tabular}{|c|c|c|c|c|}
\hline Tipe Mobil & $\begin{array}{c}\text { Sewa per jam } \\
\text { tanpa supir }\end{array}$ & $\begin{array}{c}\text { Sewa per jam } \\
\text { bersama supir }\end{array}$ & $\begin{array}{c}\text { Sewa per hari } \\
\text { tanpa supir }\end{array}$ & $\begin{array}{c}\text { Sewa per hari } \\
\text { dengan supir }\end{array}$ \\
\hline Avansa & 40.000 & 50.000 & 250.000 & 350.000 \\
\hline Rush & 50.000 & 60.000 & 300.000 & 400.000 \\
\hline Innova & 50.000 & 60.000 & 350.000 & 450.000 \\
\hline Fortuner & 60.000 & 70.000 & 450.000 & 500.000 \\
\hline Nissan & 60.000 & 70.000 & 450.000 & 500.000 \\
\hline
\end{tabular}

Jenis biaya yang dikeluarkan oleh perusahaan mobil rental yaitu biaya bahan bakar, biaya minyak pelumas, biaya pemeliharaan, biaya service, upah karyawan, dan biaya penyusutan mobil. Total biaya yang dikeluarkan perusahaan rata - rata $\mathrm{Rp}$ 20.000.000 setiap bulan.

Rata - rata pendapatan setiap mobil Rp 4.000.000 per hari dan Rp 60.000 .000 per bulan atau Rp 720.000.000 per tahun.

\section{Pembahasan}

Sistem perhitungan laba rugi pada bisnis mobil rental sangat rumit, karena pendapatan yang tidak menentu dengan tingkat resiko yang tinggi. Semua mobil yang disewakan elah di asuransikan termasuk supirnya dan mobil yang ditabrak. Pendapatan mobil rental milik PT.Banul sangat bervariasi yaitu antara Rp 3.000.000 sampai Rp 5.000.000 per bulan setiap satu unit mobil. Untuk memudahkan perhitungan, maka ditetapkan rata - rata pendapatan Rp 4.000.000 per bulan. Besar kecilnya pendapatan setiap mobil rental sangat dipengaruhi oleh permintaan pelanggan dan jenis mobil yang disewa.

Tingkat profitabilitas PT.Banul dapat dihitung dengan menggunakan laporan laba rugi setiap bulan. Hasil laporan laba rugi tersebut kemudian dianalisis dengan menggunakan persamaan yang sudah berlaku umum, yaitu profitabilitas = laba bersih dibagi pendapatan. Laba bersih apat diketahui dengan menghitung jumlah pendapatan dikurangi dengan biaya - biaya yang relevan dengan aktivitas.

Diperoleh informasi bahwa semua biaya langsung dihitung biaya per bulan, sedangkan biaya tidak langsung dihitung per tahun. Adapun biaya langsung yang terjadi diperhitungkan setiap bulan sebesar Rp 21.800.000, dengan perincian :

- Biaya cuci mobil $=$ Rp 30.000 x 15 mobil x 4k kali perbulan $=\operatorname{Rp} 1.800 .000$

- Biaya perbaikan (service) rata - rata $=R p 500.000 \times 15=R p 7.500 .000$

- Ganti oli mesin rata - rata Rp 300.000 x 15 mobil ......... = Rp 4.500 .000

- Upah supir Rp 1.000 .000 x 3 orang ..................... = Rp 3.000 .000

- Gaji karyawan Rp 1.5000.000 x 2 orang ................. = Rp 3.000 .000

Total biaya langsung mobil rental per bulan ............ $\overline{=\underline{\mathrm{Rp} 19.800 .000}}$ 
Total biaya langsung rata -rata Rp 19.800.000 per bulan. Jika dihitung per tahun, maka biaya langsung mobil rental $=\mathrm{Rp} 19.800 .000 \times 12$ bulan $=\mathrm{Rp} 237.600 .000$ per tahun.

Sedangkan biaya tidak langsung atau biaya tetap mobil rental per tahun dihitung dengan rincian sebagai berikut :

- Per ijinan mobil rental ............ = Rp 1.200 .000

- Pajak mobil untuk 15 unit per tahun........ = Rp 25.000 .000

- Biaya penyusutan mobil per tahun......... $\quad=R p 302.200 .000$

- Biaya lain - lain.................. $\quad=R p \quad 800.000$

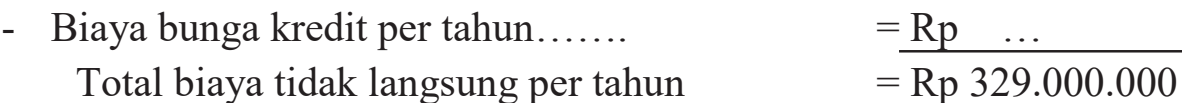

Sedangkan umur ekonomis mobil rata - rata 10 tahun. Adapun perincian harga perolehan setiap tipe mobil adalah sebagai berikut :

- Toyota Avanza 6 unit @ Rp 145.000.000 =Rp 870.000.000

- Toyota Rush6 unit @ Rp 197.000.000=Rp 1.182.000.000

- Toyota Innova 1 unit @ Rp 210.000.000 = Rp 210.000.000

- Toyota Fortuner 1 unit @ Rp 375.000.000 = Rp 375.000.000

- Nissan Extrail 1 unit @ Rp 385.000.000 = Rp 385.000.000 (+)

Total harga perolehan mobil $\quad=\underline{\underline{\mathrm{Rp} \mathrm{3} 3.022 .000 .000}}$

$$
\text { Penyusutan mobil }=\frac{\operatorname{Rp} 3.022 .000 .000}{10 \text { tahun }}=\operatorname{Rp~302.200.000~per~tahun.~}
$$

Dengan demikian, total biaya mobil rental rata - rata per tahun dapat diketahui sebagai berikut .

Total biaya langsung

$$
\begin{aligned}
& \operatorname{Rp} 237.600 .000 \\
& \operatorname{Rp} 329.200 .000 \\
& \hline \underline{\operatorname{Rp} 566.800 .000}
\end{aligned}
$$

Total biaya tidak langsung

Total biaya per tahun

Berdasarkan hasil perhitungan biaya langsung dan biaya tidak langsung, maka dapat dihitung laba bersih setiap tahun. Lebih jelasnya mengenai besarnya laba bersih dapat di liat dalam laporan laba rugi sebagai berikut. 
Tabel 02

PT.BANUL PALOPO

LAPORAN LABA RUGI

31 Desember 2009

\begin{tabular}{|c|c|c|}
\hline Keterangan & Bulan (Rp) & Tahun (Rp) \\
\hline Pendapatan & 60.000 .000 & 720.000 .000 \\
\hline Biaya langsung & 19.800 .000 & 237.600 .000 \\
\hline Biaya tidak langsung & $27434.000+$ & $329.200 .000+$ \\
\hline Total biaya & 47.234 .000 & 566.800 .000 \\
\hline Laba sebelum PPh & 12.766 .000 & 153.200 .000 \\
\hline Pajak penghasilan & 1.915 .000 & 22.980 .000 \\
\hline Laba bersih & 10.851 .000 & 130.220 .000 \\
\hline
\end{tabular}

Berdasarkan laporan laba rugi PT.Banul pada tanggal 31 Desember 2009, diperoleh pendapatan rental mobil per bulan Rp 60.000.000 dan per tahun sebesar Rp 720.000.000, kemudian dikurangai biaya langsung dan biaya tidak langsung serta pajak penghasilan, sehingga dipewroleh laba bersih Rp 10.851.000 per bulan dan Rp 130.220.000 per tahun.

Analisis profitabilitas dan rentabilitas yang dicapai oleh PT.Banul selama tahun 2009 adalah sebagai berikut.

Laba Bersih

Ratio profitabilitas $=\frac{}{\text { Total Pendapatan }} \quad \times 100 \%$

Rp 130.220.000

Ratio Profitabilitas $=\frac{}{\operatorname{Rp} 720.000 .000} \times 100 \%=\operatorname{Rp~18,09\% }$

Hasil analisa Profitabilitas pada tahun 2009 diperoleh 18,09\% artinya bahwa setiap pendapatan Rp 100 atau 100\% mampu memperoleh laba bersih sebesar Rp 18,09 atau $18,09 \%$.

Analisa rentabilitas bertujuan untuk mengetahui kemampuan perusahaa menghasilkan laba berdasarkan total asset yang dipakai setiap tahun. Diketahui laba bersih Rp 130.220.000 dan total asset sebesar Rp 3.022.000. Maka analisa rentabilitas dapat dihitung dengan menggunakan rumus sebagai berikut.

Laba bersih

Rentabilitas $=\frac{\text { Total asset }}{\text { T } 100 \%}$

Rp 130.000 .000

Rentabilitas $=\longrightarrow \quad$ x $100 \%=4,31 \%$

Rp 3.022.000.000 
Berdasarkan hasil analisa ratio rentabilitas sebesar 4,31\% artinya bahwa setiap total asset Rp 100 hanya mampu menghasilkan Rp 4,31 per tahun. Dengan demikian, hasil yang dicapai sangat rendah dibandingkan dengan suku bunga tabungan di bank yang mencapai $6 \%$ per tahun.

\section{Penutup}

Kesimpulan penelitian ini adalah bahwa PT.Banul Palopo adalah usaha bisnis yang bergerak di bidang rental mobil. Jumlah mobil yang dimiliki sebanyak 15 unit dengan total harga Rp 3.022.000.000, total pendapatan per bulan Rp 60.000.000 atau Rp 720.000.000 per tahun dengan total biaya langsung dan biaya tidak langsung Rp 566.800.000. Total laba setelah laba penghasilan sebesar Rp 130.220.000 per tahun. Berdasarkan ratio di atas, maka ratio profitabilitas PT.Banul pada tahun 2009 sebesar $18,09 \%$ artinya bahwa setiap pendapatan Rp100 mampu menambah modal perusahaan sebesar $\mathrm{Rp}$ 18,09. Adapun saran dari penelitian ini adalah bahwa disarankan kepada Direktur PT.Banul agar tetap mempertahankan laba sesudah pajak yang dicapai sekarang dan ditingkatkan ratio profitabilitasnya, dengan cara menghemat biaya dan meningkatkan pendapatan dari bisnis rental mobil. Pendapatan rental mobil dapat ditingkatkan dengan cara melakukan promosi dan kebijakan dalam negosiasi penetapan tariff mobil rental secara proporsional waktu pemakaian mobil rental tersebut. Pendekatan kebijakan dan promosi pribadi yang tepat dapat meningkatkan permintaan mobil rental, sehingga dapat menambah pendapatan dan laba bersih setiap hari.

\section{Daftar Pustaka}

Adisurupto, Gunawan. 1992. Biaya Perencanaan dan Pengabdian pada Perusahaan, Penerbit BPFE, Yogyakarta.

Arief, Srituah. 1993. Metodologi Penelitian Ekonomi. UI Press, Jakarta.

Alwi, Syafaruddin. 1994. Alat - Alat Analisis dalam Pembelajaran. Edisi Revisi, Andi offset, Yogyakarta.

Baridwan, Zaki. 1992. Intermediate Accounting. FE-UGM, Yogyakarta.

Edward J.Blocher, Kung H.Chen \& Thomas W.Lin, 2000. Manajemen Biaya, Edisi Pertama, Penerbit Salemba Empat, Jakarta.

Erich A.Helfert. 1995. Analisis Laporan Keuangan. Edisi ketujuh, Penerbit Erlangga, Jakarta.

Garrisson, Ray .H. 1997. Akuntansi Manajemen. Bandung: ITB Bandung. 
Husnan, Suad dan Anny Pudjiastuti. 1998. Dasar - Dasar Manajemen Keuangan. Penerbit UPP AMP YKPN, Yogyakarta.

Husnan, Suad. 1996. Pembelanjaan Perusahaan. Edisi Keempat, Penerbit Liberty, Yogyakarta.

Husnan, Suad. 2000. Manajemen Keuangan, Teori dan Penerapan (Keputusan Jangka Panjang dan Jangka Pendek), buku 1 \& 2, Edisi 4, Penerbit BPFE, Yogyakarta.

Harahap, Syafri Sofyan. 1997. Analisis Kritis atas Laporan Keuangan. Penerbit PT.Raja Grafindo Persada, Jakarta.

Indrio dan Basri. 1998. Manajemen Keuangan. Edisi pertama, Penerbit Liberty, Yogyakarta.

Lukman Syamsuddin. 1997. Manajemen Keuangan Perusahaan, Edisi kedua, PT.Raja Grafindo Persada, Jakarta.

Mulyadi. 1995. Akuntansi Biaya. Edisi ketiga, LPBFE UGM, Yogyakarta.

Munawir, S. 2002. Analisa Laporan Keuangan. Edisi IV, Liberty, Yogyakarta.

Murti Sumarni \& John Soeprihanto. 1994. Pengantar Bisnis (Dasar - Dasar Ekonomi Perusahaan). Edisi kelima, Penerbit Liberty, Yogyakarta.

Muhadjir, Noeng. 2002. Metode Penelitian Kualitatif, Sarasin. Liberty, Yogyakarta.

Suad Husnan \& Enny Pudjiastuti,. 1998. Dasar - Dasar Manajemen Keuangan. Erlangga, Jakarta.

Soemita, A.R. 1998. Akuntansi Biaya dan Harga Paket. Jilid I Akuntansi, Bandung.

Riyanto, Bambang. 1995. Dasar-Dasar Pembelanjaan Perusahaan. Penerbit BPFE, Yogyakarta.

Riyanto, Bambang. 1997. Dasar - Dasar Pembelanjaan Perusahaan. Edisi keempat, Penerbit BPFE, Yogyakarta.

Syamsuddin, Lukman. 1995. Manajemen Keuangan Perusahaan. Penerbit YP2LM, Hanindita, Yogyakarta. 